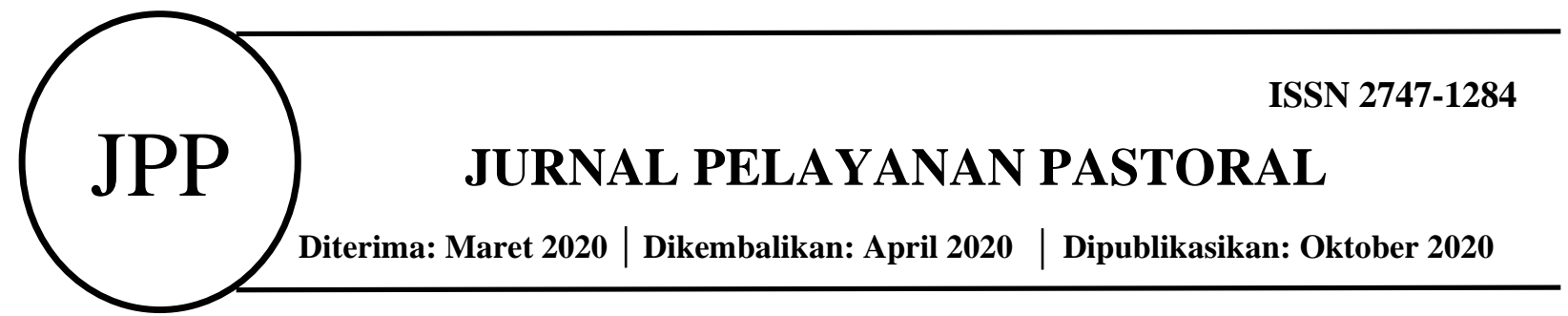

\title{
EFEKTIVITAS MEDIA DEKAK-DEKAK PADA OPERASI PENJUMLAHAN 1-10 BAGI SISWA TUNAGRAHITA RINGAN KELAS 1 SLB-YPAC KOTA MALANG
}

\author{
Neny Yuniarti*1, Yohanes Subasno*2 \\ ${ }^{*}$ SLB YPAC Kota Malang \\ ${ }^{2}$ Sekolah Tinggi Pastoral -IPI Malang \\ Jurusan Pastoral Sosial, Prodi Pelayanan Pastoral \\ e-mail: ${ }^{1}$ yuniartineny10@gmail.com dan ${ }^{2}$ subasno@gmail.com
}

\begin{abstract}
Abstrak
Peserta didik berkebutuhan khusus tunagrahita ringan memiliki keterbatasan intelektual, terutama dalam berpikir abstrak. Hal itu menjadi faktor penyebab utama rendahnya prestasi belajar khususnya bidang berhitung (matematika). Pemilihan media belajar yang sesuai dengan karakteristik tunagrahita ringan sangat penting untuk menjembatani unsur abstrak dan konkret sehingga mudah dipahami. Media dekakdekak menjadi salah satu media pembelajaran yang digunakan dalam operasi penjumlahan bagi tunagrahita. Tujuan penelitian ini adalah mengukur efektifitas penggunaan media dekak-dekak pada operasi penjumlahan 1-10 bagi siswa tunagrahita ringan kelas 1 Sekolah Luar Biasa. Penelitian ini merupakan penelitian tindakan kelas, yang memberikan batasan efektifitas berdasar kriteria ketuntatasn minimal (KKM) 75 poin nilai. Seorang siswa, guru kelas, dan seorang pengamat berpartisipasi dalam penelitian ini. Hasil penelitian mencatat nilai 50 poin pada pra siklus, nilai 70 poin pada siklus pertama, dan nilai 80 poin pada siklus kedua. Dengan demikian media dekak-dekak efektif untuk diterapkan pada pembelajaran operasi penjumlahan 1-10 bagi siswa tunagrahita ringan.
\end{abstract}

Kata Kunci: media dekak-dekak, operasi penjumlahan, tunagrahita.

\begin{abstract}
Students with intellectual disabilities have limited thinking, especifically in abstract. That is the main factor causing the low learning achievement specifically in the field of arithmetic (mathematics). The selection of learning media that is suitable for the characteristics of intellectual disabilities is very important to bridge the abstract and concrete so that it is easy to understand. Media "dekak-dekak" becomes one of the learning media that is used in the sum operations for student with intellectual disability. The purpose of this study is to measure the effectiveness of the use of media "dekak-dekak" in the sum operation 1-10 for mild intellectual disability students in the 1st grade of Special School. This research is a class action research, which limits effectiveness based on the completeness minimum criteria (KKM) of 75 value points. A student, class teacher, and an observer participated in this study. The results of the study recorded the value of 50 points in the pre-cycle, the value of 70 points in the first cycle, and the value of 80 points in the second cycle. Thus, the media "dekak-dekak" effectively to be applied to the learning of the sum operations 1-10 for students with mild intellectual disabilities.
\end{abstract}

Keywords: media “dekak-dekak", sum operation, intellectual disability. 


\section{PENDAHULUAN}

Setiap anak mempunyai hak yang sama untuk dapat mengakses layanan pendidikan. Hal ini tertuang dalam Undang-Undang No. 20 Tahun 2003 tentang Sistem Pendidikan Nasional, pada pasal 32 disebutkan bahwa: "pendidikan khusus (Pendidikan Luar Biasa) merupakan pendidikan bagi peserta didik yang memiliki tingkat kesulitan dalam mengikuti proses pembelajaran karena kelainan fisik, emosional, mental, dan sosial". Ketetapan tersebut memberi landasan yang kuat bahwa anak berkebutuhan khusus berhak memperoleh kesempatan yang sama sebagaimana yang diberikan kepada anak-anak pada umumnya dalam hal pendidikan dan pengajaran. Kenyataan ini juga didukung oleh adanya perkembangan ilmu pengetahuan dan teknologi, sehingga "pendidikan sangat dirasa penting untuk menunjang kebutuhan manusia dalam menghadapi persoalan hidup". (Gunarhadi 2005, 88)

Salah satu anak berkebutuhan khusus adalah anak tunagrahita ringan, yang dalam sistem pendidikan di Indonesia termasuk di dalam SLB/C. Anak tunagrahita adalah anak yang mempunyai gangguan berupa keterbelakangan pada ranah intelegensi yaitu memiliki kecerdasan dibawah rata-rata dari anak-anak pada umumnya. Disamping itu, mereka juga mengalami keterbelakangan dalam menyesuaikan diri dengan lingkungan dan mengalami gangguan pada emosionalnya serta kurang cakap dalam memikirkan hal-hal yang bersifat abstrak. Hal-hal itulah yang menyebabkan perkembangan intelegensi anak menjadi tertinggal atau bahkan terhambat.

Pendidikan Luar Biasa bertujuan untuk membekali siswa berkebutuhan khusus untuk dapat berperan aktif dalam masyarakat. Dalam PP No.72 tahun 1991 dijelaskan bahwa: "Pendidikan luar biasa bertujuan membantu mengembangkan sikap, pengetahuan, dan ketrampilan sebagai pribadi maupun anggota masyarakat dalam mengadakan hubungan timbal-balik dengan lingkungan sosial, budaya dan alam sekitar serta dapat mengembangkan kemampuan dalam dunia kerja atau mengikuti dunia pendidikan lanjutan".

Seperti yang pernah dinyatakan bahwa matematika adalah bahasa simbolis yang memiliki fungsi praktis untuk mengekspresikan hubungan-hubungan kuantitatif Menurut (Delpie 2009, 2). Matematika, yang didalamnya terdapat aspek berhitung, digunakan dan diajarkan sebagai salah satu kurikulum karena merupakan sarana untuk memecahkan masalah dalam kehidupan seharihari. Kegiatan manusia sehari-hari memerlukan keterampilan yang berkaitan dengan berhitung tidak terkecuali pada kelompok anak tunagrahita ringan dan tunagrahita sedang. Keterbatasan yang dimiliki oleh anak tunagrahita ringan maupun sedang dapat menjadi faktor rendahnya prestasi belajar anak dalam bidang akademik khususnya pada mata pelajaran matematika. Hal tersebut dipengaruhi oleh beberapa faktor antara lain: pemahaman anak tunagrahita ringan dan sedang yang kurang, terutama dalam bidang yang tidak konkret alias abstrak, daya ingat yang rendah, daya pikir (intelegensi) yang lemah, tingkat konsentrasi dan emosi yang labil serta cepatnya anak tunagrahita merasa jenuh dalam belajar dikelas. Faktor tersebut sesuai dengan karakteristik anak tunagrahita yang pada umumnya yang dapat menjadi halangan terbesar untuk belajar matematika.

Pandangan yang telah muncul dari dulu menganggap bahwa matematika merupakan mata pelajaran yang sulit, rumit, menakutkan dan juga membosankan. Nyatanya memang demikian, karena ada banyak sekali siswa yang tidak menyukainya. Padahal sesungguhnya unsur-unsur matematika itu menyertai kita dalam kehidupan sehari-hari dan banyak manfaatnya seperti dalam hal jual-beli, menghitung barang dan sebagainya. Selain itu kurangnya minat dan ketertarikan siswa dalam belajar matematika juga sangat berpengaruh.

Pemilihan media yang sesuai dengan karakteristik anak tunagrahita sedang dan ringan sangat penting guna mengurangi beberapa ancaman terhadap perasaan negatif peserta didik terhadap pelajaran matematika. Saat kegiatan belajar mengajar matematika berlangsung, media 
merupakan suatu bagian yang disatukan pada penyajian pembelajaran, yang memberikan sumbangan untuk mencapai tujuan pada pembelajaran itu sendiri. Media juga dapat menggantikan kata-kata verbal yang sering bersifat abstrak. Media juga dapat membantu meningkatkan dan merangsang minat siswa tunagrahita ringan untuk belajar.

Dalam penelitian ini, digunakan media berupa alat yang disebut dekak-dekak untuk meningkatkan belajar matematika pada operasi penjumlahan 1-10 untuk siswa tunagrahita ringan (C) kelas D1 di SLB/C YPAC Malang. Media dekak-dekak berupa media konkret yang dapat diraba, sehingga dapat menyampaikan pesan-pesan pembelajaran secara nonverbal-visual. Media dekak-dekak ini diberikan agar dapat digunakan sebagai upaya untuk mempermudah siswa dalam mengerjakan matematika pada operasi penjumlahan 1-10 angka saat di kelas.

\section{METODE PENELITIAN}

Penelitian ini merupakan penelitian tindakan kelas yang dipahami sebagai suatu penelitian tindakan (action research) yang dilakukan oleh guru sekaligus sebagai peneliti di kelasnya bersama dengan orang lain (colaborator) dengan jalan merancang, melaksanakan dan merefleksikan tindakan secara kolaboratif dan partisipasif yang bertujuan untuk memperbaiki atau meningkatkan mutu (kualitas) proses pembelajaran di kelas melalui suatu tindakan (treatment) tertentu dalam suatu siklus" (Kunandar 2008, 44). Berdasarkan pemahaman tersebut, peneliti melakukan modifikasi langkah-langkah penelitian tindakan kelas yang meliputi pra siklus, siklus 1 dan siklus 2 .

Pra siklus merupakan kegiatan belajar dimana siswa tunagrahita mengalami kesulitan belajar dengan media belajar sebelumnya. Pada pra siklus ini dilakukan tes yang digunakan sebagai data awal (Pra Tes). Siklus 1 merupakan tindakan yang terdiri dari Perencanaan, meliputi penetapan materi pembelajaran (operasi penjumlahan dengan media dekak-dekak) dan penetapan alokasi waktu pelaksanaannya. Tindakan, meliputi seluruh proses kegiatan belajar mengajar operasi penjumlahan dengan media dekak-dekak. Observasi, dilaksanakan bersamaan dengan proses pembelajaran meliputi keterlaksanaan tindakan guru, keaktifan siswa dalam pembelajaran dan hasil belajar siswa. Refleksi, meliputi kegiatan analisi hasil pembelajaran dan sekaligus menyusun rencana perbaikan pada siklus berikutnya. Siklus 1 dilaksanakan sebanyak tiga kali pertemuan dan pertemuan ketiga digunakan sebagai Post Test. Siklus 2 adalah kegiatan yang sama dengan siklus 1 ditambah dengan pengulangan-pengulangan materi (hal ini dilakukan sebagai bentuk penanganan untuk mengatasi karakterisitik anak tunagrahita) dan pemberian soal yang bervariasi untuk memastikan bahwa siswa menguasai penjumlahan 1-10. Siklus 2 ini dilaksanakan 3 kali pertemuan; dan pada pertemuan yang terakhir digunakan sebagai Post Test.

Diagram 1: Siklus Penelitian Tindakan Kelas

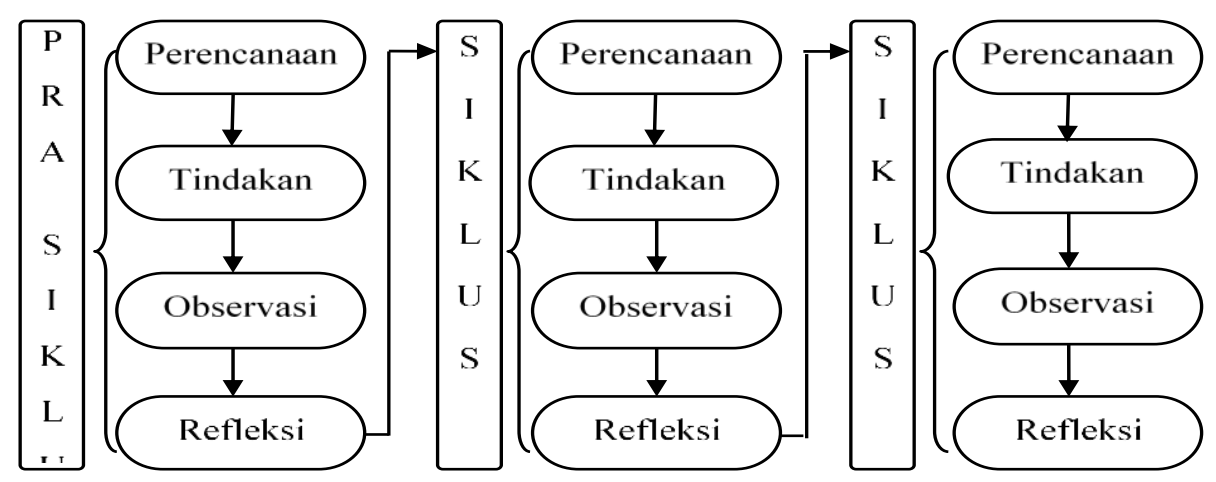


Metode pengumpulan data dilakukan dengan observasi yakni melakukan pencatatan hasil tes awal (Pra Siklus) sampai dengan akhir penelitian (Siklus 2) dengan bantuan seorang peneliti lain sebagai mitra peneliti (collaborator). Observasi dalam penelitian ini menggunakan 3 macam instrumen, yaitu instrumen untuk menilai aktifitas guru, instrumen untuk menilai aktifitas siswa, instrumen penilaian proses. Ketiga macam instrumen memiliki 4 pilihan atau opsi penilaian, dengan pembobotan sebagai berikut:

\section{Tabel 1: Opsi dan Pembobotan}

\begin{tabular}{l|l|l}
\hline OPSI & BOBOT & KETERANGAN \\
\hline A & 3 & Sangat Baik \\
\hline B & 2 & Baik \\
\hline C & 1 & Cukup \\
\hline D & 0 & Kurang \\
\hline
\end{tabular}

Dengan adanya pembobotan untuk tiap item pada instrumen observasi maka dimungkinkan diperoleh hasil maksimal atau kondisi ideal, baik pada aktifitas guru maupun untuk aktifitas siswa. Hasil maksimal yang dimaksud jika pada keseluruhan item memiliki hasil penilaian A yang berbobot 3. Sungguhpun demikian hasil maksimal atau ideal akan sulit dicapai. Oleh karena itu, peneliti memberikan batasan bahwa kondisi penelitian dinyatakan ideal apabila total nilai dengan pembobotan pada observasi untuk aktifitas guru dan total nilai pembobotan untuk aktifitas siswa, masing-masing mencapai sekurang-kurangnya $75 \%$ dari kondisi ideal. Sedangkan untuk mengukur efektifitas operasi penjumlahan 1-10 dengan media dekak-dekak, peneliti menggunakan evaluasi atau tes, yang hasilnya dipakai untuk memperoleh data kemampuan siswa dalam operasi penjumlahan dengan media dekak-dekak. Siswa dinyatakan berhasil atau tuntas belajar (efektif) bila mencapai nilai 75 atau lebih. Pada bagian refleksi dilakukan analisis data mengenai proses, masalah dan hambatan yang dijumpai, kemudian dilanjutkan dengan pelaksanaan tindakan yang dilaksanakan. Salah satu aspek yang penting dari kegiatan refleksi adalah evaluasi terhadap keberhasilan dan pencapaian tujuan.

Pengolahan data dilakukan dengan menggunakan penghitungan prosentase. Untuk itu rumus yang digunakan adalah $\mathrm{F}$ Prosen $(\mathrm{P}=\mathrm{F} / \mathrm{N}$ x 100\%) dimana $\mathrm{P}$ adalah prosentase, $\mathrm{F}$ adalah jumlah total frekuensi penilaian item observasi dikali pembobotan, dan $\mathrm{N}$ adalah jumlah total item observasi ideal.

Analisa data dalam penelitian ini menggunakan analisis deskriptif kualitatif, di mana data disampaikan secara deskriptif yang mengungkapkan tentang pelaksanaan pembelajaran operasi hitung dengan media dekak-dekak, hasil observasi menjadi data pendukung di dalam menganalisa kondisi saat pembelajaran berlangsung. Sedangkan hasil tes pada pra siklus dan hasil tes pada siklus 2 menjadi sumber data utama untuk menentukan efektifitas pembelajaran operasi penjumlahan 1-10 dengan menggunakan media dekak-dekak. Selebihnya, analisa data juga dilakukan secara visual grafis yakni menampilkan grafik pre-test dan post-test.

\section{HASIL DAN PEMBAHASAN}

Pada pra siklus, siswa bernama RPP mendapatkan nilai 50 karena tidak aktif dalam pembelajaran, mudah bosan dan mudah beralih perhatiannya pada teman-temannya di kelas. 
Dalam proses pembelajaran, guru selalu memberikan motivasi dan dorongan agar siswa aktif dalam pembelajaran dan memberikan tanda bintang setiap siswa menjawab pertanyaan dengan tepat. Namun ketepatan dalam menjawab pertanyaan masih kurang. Siswa masih kesulitan untuk menggunakan media yang telah disiapkan dalam Rencana Pelaksanan Pembelajaran, yakni menggunakan media belajar berupa sedotan. Letak kesulitan dengan media ini adalah pada saat diberikan soal, siswa cenderung menggunakan media ini untuk bermain atau dilempar-lemparkan. Refleksi berdasarkan pengamatan mengenai aktifitas siswa pada pra siklus menunjukkan adanya kelemahan yang ditemukan saat pembelajaran operasi penjumlahan 1-10, yaitu siswa kurang aktif dalam pembelajaran operasi penjumlahan 1-10. Siswa mengalami kebingungan dan terkesan sangat sulit saat mengerjakan operasi penjumlahan 1-10. Hal ini dikarenakan pada saat guru mengajar, hanya digunakan media sedotan yang kurang menarik perhatian siswa. Di samping itu selama proses pembelajaran siswa menunjukkan sikap yang negatif, yaitu saat tidak bisa mengerjakan soal cenderung menggunakan media pembelajaran sebagai alat bermain.

Pada Siklus Pertama, penilaian terhadap aktivitas (keaktifan) siswa selama proses pembelajaran diperoleh hasil 80\%, yang berarti perhatian dan motivasi siswa cukup bagus. Namun demikian, pada lembar observasi diketahui bahwa siswa kurang dapat memanfaatkan waktu secara baik. Sementara itu, berdasarkan hasil observasi tindakan guru dalam proses pembelajaran diperoleh capaian 100\%, yang berarti tindakan guru mencapai kondisi ideal untuk proses pembelajaran. Selanjutnya pada saat dilakukan observasi selama proses perlakuan atau treatment diperoleh prosentase $80 \%$, hal ini berarti siswa sudah bisa mengetahui cara atau menggunakan media dekak-dekak untuk melakukan penjumlahan1-10, tetapi masih ada jawaban yang kurang tepat. Hasil test operasi penjumlahan 1-10 menggunakan media dekak-dekak diperoleh nilai sebesar 70. Dengan kata lain, pada siklus pertama telah dicapai peningkatan sebesar 20 poin nilai, yang merupakan selisih antara pre-test dan post-test (70-50).

Pada siklus kedua, hasil observasi aktifitas (keaktifan) siswa selama proses pembelajaran diperoleh hasil 100\%, yang berarti perhatian dan motivasi sangat bagus karena mencapai kondisi yang ideal untuk suatu proses pembelajaran. Selanjutnya berdasarkan hasil observasi, tindakan guru dalam proses pembelajaran juga dapat mencapai 100\%, yang berarti tindakan guru mencapai kondisi ideal untuk proses pembelajaran. Berdasarkan observasi penilaian proses pembelajaran (treatment) siswa dengan media dekak-dekak terlaksana 100\%, hal ini menunjukkan situasi dan kondisi serta proses pembelajaran yang ideal, yang tercermin pada keseluruhan proses, di mana siswa bisa mengikutinya dengan baik. Hal terpenting lainnya yang ditunjukkan oleh siswa adalah dengan penguasaan terhadap media dekak-dekak untuk melakukan penjumlahan 1-10. Sedangkan ketuntasan belajar berdasarkan penilaian proses dan hasil tes tulis telah melampui indikator keberhasilan tindakan atau nilai ketuntasan belajar yaitu mencapai 80. Dengan demikian, pada siklus kedua ini, kemampuan siswa dalam operasi penjumlahan 1-10 mengalami kenaikan nilai sebesar 10 poin, yang merupakan selisih pencapaian nilai dari siklus pertama dan siklus kedua.

Secara grafis dapat ditunjukkan kenaikan kemampuan atau prestasi siswa dalam operasi penjumlahan 1-10 setelah diberi tindakan atau treatment dengan menggunakan media belajar berupa dekak-dekak:

\section{Grafik 1: Peningkatan kemampuan operasi penjumlahan 1-10 setelah diberi tindakan}




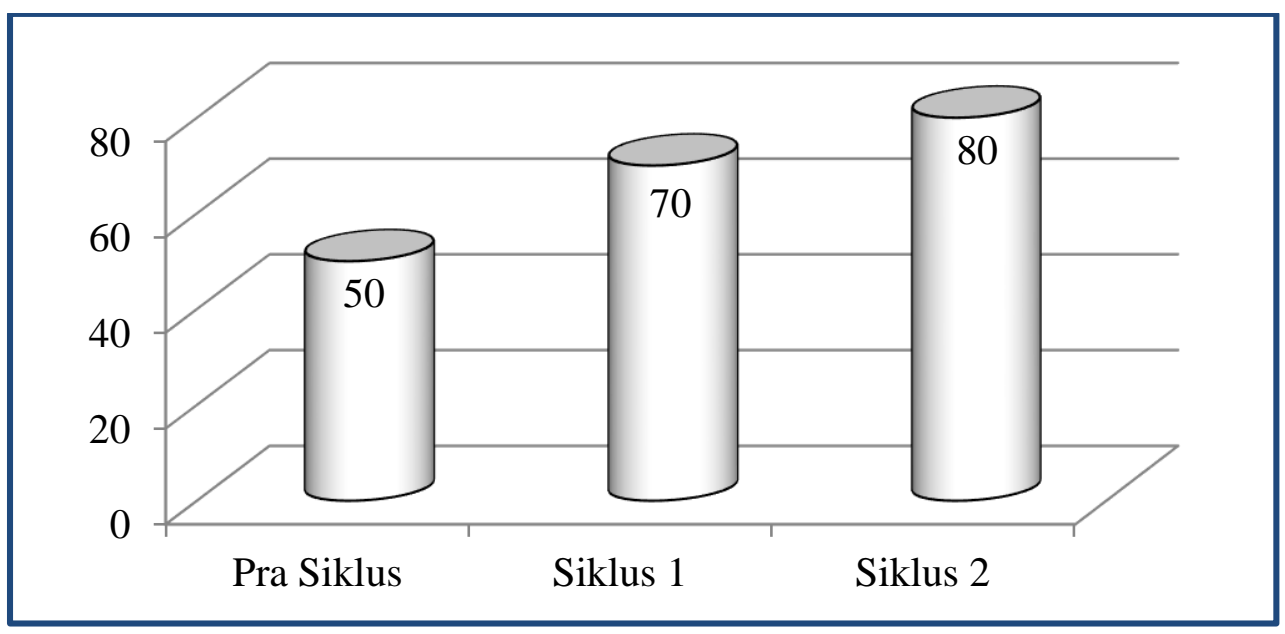

\section{KESIMPULAN}

Kesimpulan: (1) Media dekak-dekak adalah salah satu media pembelajaran yang digunakan untuk pembelajaran matematika pada operasi penjumlahan 1-10 pada siswa tunagrahita ringan di SLB YPAC Kota Malang; (2) Dengan media dekak-dekak terbukti efektif dan atau meningkatkan hasil belajar operasi penjumlahan 1-10 pada siswa tunagrahita ringan di SLB YPAC Kota Malang; (3) Peningkatan atau efektifitas pembelajaran operasi penjumlahan 1-10 ditunjukkan dengan adanya peningkatan pencapaian poin nilai tes siswa, yakni dari 50 poin pada pra siklus, meningkat menjadi 70 poin pada siklus 1, dan lebih meningkat lagi menjadi 80 poin pada siklus 2.

Saran: (1) Pendekatan pembelajaran operasi penjumlahan 1-10 dengan media dekakdekak ini dapat dijadikan alternatif atau acuan untuk pembelajaran matematika khususnya pada operasi penjumlahan 1-10 di SLB lainnya; (2) Variasi dalam pembelajaran perlu dilakukan agar tidak terjadi kejenuhan pada saat siswa melakukan proses pembelajaran; (3) Guru harus selalu berusaha meningkatkan dan memperbaiki kualitas diri dalam menjalankan tugasnya sebagai pengajar sekaligus pendidik.

\section{DAFTAR PUSTAKA}

Amin, M. 1995. Ortopedagogik Anak Tunagrahita. Jakarta: Departemen Pendidikan dan Kebudayaan.

Arsyad, Azahar. 2009. Media Pembelajaran. Jakarta: PT. Raja Grafindo.

Badan Standar Nasional Pendidikan. 2006. Model Penilaian Kelas. Jakarta: Departemen Pendidikan Nasional.

Delphie, Bandi. 2006. Pembelajaran Anak Tunagrahita (suatu pengantar dalam Pendidikan Khusus). Bandung: PT. Refika Aditama.

Departemen Pendidikan dan Kebudayaan. 2006. Standar Kompetensi dan Kompetensi Dasar Kurikulum SDLB C. Jakarta: Departemen Pendidikan dan Kebudayaan.

Gunarhadi. 2005. Penanganan Anak Sindroma Down Dalam Lingkungan Keluarga Dan Sekolah. Jakarta: Departemen Pendidikan Nasional, Direktorat Jenderal Pendidikan Tinggi,

Subdirektorat Pembinaan Pendidikan Tenaga Kependidikan dan Ketenagaan Perguruan Tinggi.

Hamalik, Oemar. 2009. Media Pendidikan. Bandung: Citra Aditya Bakti.

Heruman. 2008. Model Pembelajran Matematika di Sekolah Dasar. Bandung: PT. Remaja

Rosdakarya Offset. 
Hurlock, Elizabeth B. 1980. Psikologi Perkembangan Anak, Jilid 1-2. Jakarta: Penerbit Airlangga. Pusat Bahasa Edisi Keempat Departemen Pendidikan Nasional. 2008. Kamus Besar Bahasa Indonesia. Jakarta: PT. Gramedia, Pustaka Utama.

Runtukahu, J. Tombokan. 1996. Pengajaran Matematika Bagi Anak Berkesulitan Belajar. Jakarta: Departemen Pendidikan dan Kebudayaan. 